\title{
Grooming in the brown tree snake (Boiga irregularis)
}

\author{
THOMAS M. DUNN \\ Allegheny College, Meadville, Pennsylvania \\ and \\ DAVID CHISZAR \\ University of Colorado, Boulder, Colorado
}

\begin{abstract}
Brown tree snakes, Boiga irregularis, exhibited an elevated frequency of jaw rubbing when a small quantity of petroleum jelly was placed on their lips. Jaw rubbing has the effect of removing foreign material from the lips, and it represents a behavior that cleans and maintains a particular part of the body surface. Although few such behaviors have been reported in reptiles, we suspect that many exist and simply have gone unnoticed because herpetologists have attached no theoretical significance to them.
\end{abstract}

Two relatively recent reviews of behaviors that care for body surfaces mentioned few herpetological examples (Borchelt, 1980; Grier \& Burk, 1992). Although the grooming activities of endothermic vertebrates are more complex and more frequently executed than is the case in reptiles, it is nevertheless true that the latter animals exhibit a variety of behaviors that clean or otherwise care for body surfaces. For example, when cotton-tipped applicators are used to place chemical cues on the lips of snakes (see Burghardt, 1970, for a review), several responses are common. First, if the chemicals are derived from prey organisms, snakes of many species will often attack the applicators as if they were prey. Second, if the chemicals are noxious, snakes initially attempt to flee, and later they will rub their jaws against rocks or other objects as if trying to remove the offending material. Also, this jaw rubbing is sometimes seen after a snake has devoured a prey item, suggesting that the behavior removes not only noxious compounds but also the integumentary residues of prey. Having seen all of these behaviors in brown tree snakes, we wondered if a situation could be created in which jaw rubbing would occur frequently and reliably, perhaps giving rise to a useful research paradigm. This paper describes one such situation.

\section{EXPERIMENT 1}

\section{Method \\ Subjects were 10 individually caged adult Boiga irregularis selected randomly from our colony of 30 individuals. Each snake was observed twice (ITI = 1 week). On the control trial, the snake was touched on the lips with a cotton swab that had been dipped into tap water at room temperature $\left(26^{\circ} \mathrm{C}\right)$. On the experimental trial, the swab contained un- scented petroleum jelly, also at room temperature. Applicators were re- moved immediately after they were touched to the snake's left and right}

Correspondence should be addressed to David Chiszar, Department of Psychology, Campus Box 345, University of Colorado, Boulder, CO 80309-0345. lips, and the snake was observed for the next $10 \mathrm{~min}$. Dependent variables were the number of times the snake rubbed its jaw against any surface in its cage and the number of tongue flicks. All trials were conducted during photophase (0700-1900 h). Five snakes received the control trial first, and the remaining 5 snakes received the experimental trial first.

\section{Results}

Table 1 shows that $B$. irregularis responded strongly to petroleum jelly. The difference between the rates of tongue flicking in the two conditions was significant by a paired $t$ test $[t(9)=2.28, p<.05]$, as was the difference in the number of jaw rubs $[t(9)=4.22, p<.05]$. Hence, petroleum jelly applied to the lips resulted in an increase in lingual sampling, a chemosensory behavior indicating detection of the substance. The elevated frequency of jaw rubbing presumably reflected attempts by snakes to remove the petroleum jelly.

\section{EXPERIMENT 2}

Since petroleum jelly applied to the lips of brown tree snakes produced increased autogrooming, we conducted Experiment 2 to ascertain if the same result would occur if petroleum jelly was applied elsewhere on the snake's body.

\section{Method}

Subjects were 6 adult $B$. irregularis selected randomly from the colony. Maintenance conditions were identical to those described above. Each snake was touched just past the middle of its length with a cotton swab containing petroleum jelly, which was smeared over a $1-\mathrm{cm}^{2}$ lateral area. During the next $10 \mathrm{~min}$, we recorded the number of times the snake rubbed the affected part of its body on any surface. For a control, the same snakes received petroleum jelly on their jaws as in Experiment 1. Three snakes received each order of presentation (ITI $=1$ week).

\section{Results}

No snake in either condition rubbed the posterior part of its body against any surface. Jaw rubbing, however, 
Table 1

Number of Tongue Flicks and Jaw Rubs in 10 Brown Tree Snakes That Were Touched on the Lips with Cotton Swabs Containing Tap Water (Control) or Petroleum Jelly (Experimental)

\begin{tabular}{|c|c|c|c|c|}
\hline \multirow{3}{*}{ Condition } & \multicolumn{4}{|c|}{ Measure } \\
\hline & \multicolumn{2}{|c|}{ Tongue Flicks } & \multicolumn{2}{|c|}{ Jaw Rubs } \\
\hline & $M$ & $S E$ & $M$ & $S E$ \\
\hline Control & 98.2 & 46.0 & 0.1 & 0.1 \\
\hline Experimental & 186.5 & 56.1 & 3.3 & 0.7 \\
\hline
\end{tabular}

was seen in the control condition $(M=1.2$ per trial), but not in the experimental condition $[t(5)=2.40, .10>$ $p>.05]$. Although snakes again rubbed their jaws against objects, presumably to remove the petroleum jelly, no snake rubbed the posterior section of its body against objects to achieve the same effect.

\section{GENERAL DISCUSSION}

The topography of the jaw-rubbing behavior observed in this study was similar to the actions seen when noxious materials were applied to snakes' lips and when snakes had swallowed prey. Also, a very similar behavior occurs during ecdysis. Here the snake rubs its jaws against objects, splitting the most anterior portion of the old skin. After a split appears along the snout, the snake literally crawls out of the old skin, turning it inside out in the process. Finally, snakes use a similar behavior to push their way into tight places or to push their way out of confinement. Lorenz (1981) discussed behaviors that serve more than one teleonomic function or depend upon multiple motivations, using the term "Werkzeugbewegungen" (tool activities or behavioral tools). We suggest that jaw rubbing in snakes is a behavior of this sort, and that perhaps it is analogous to bill wiping in some birds and to muzzle rubbing in some mammals.

Even if topographic features turn out to distinguish the various behaviors described above, it remains certain that a self-cleaning behavior occurs in snakes. The present experimental situation could, therefore, be used to study the effects on the behavior of such processes as habituation, sensitization, and classical conditioning. This situation could also be used to identify the receptors that detect foreign substances and the interneurons that activate jaw rubbing.

No evidence was found for a body-rubbing analogue to jaw rubbing. Either the body is not used in this manner, or our stimulus was not strong enough to trigger the motor pattern. We suspect that the latter is true, because snakes of numerous species are known to rub their bodies in other contexts.

Jaw rubbing is relatively easy to elicit, and it occurs with reasonable frequency under nonexperimental conditions (e.g., during and after feeding). There are other ophidian motor patterns, however, that appear to serve cleaning or comfort roles but that occur less commonly than jaw rubbing. Although human observers have so far not been especially keen at discerning such behaviors and the motivational states they represent, some prey organisms are apparently quite good at this (Khan \& Tasnim, 1992). Accordingly, research on the grooming and comfort patterns of snakes is likely to be no less informative than similar research on other vertebrates (see references cited by Borchelt, 1980, and Grier \& Burk, 1992).

\section{REFERENCES}

Borchelt, P. L. (1980). Care of the body surface (COBS). In M. R. Denny (Ed.), Comparative psychology: An evolutionary analysis of animal behavior (pp. 363-384). New York: Wiley.

BURGHARDT, G. M. (1970). Chemical perception in reptiles. In J. W. Johnson, Jr., D. G. Moulton, \& A. Turk (Eds.), Communication by chemical signals (pp. 241-308). New York: Appleton-Century-Crofts.

GRIER, J. W., \& BURK, T. (1992). Biology of animal behavior. St. Louis: Mosby Year Book.

KHAN, M. S., \& TASNiM, R. (1992). On a strange escape behaviour shown by common Pakistani toad, Bufo stomaticus, to an ophidian predator. The Snake, 24, 74-76.

LORENZ, K. Z. (1981). The foundation of ethology. New York: SpringerVerlag.

(Manuscript received April 1, 1993.) 